\title{
Determination of Melamine in Fresh Milk by Electrochemistry with Solid Phase Microextraction at Bismuthyl Chloride Modified Graphite Epoxy Composite Electrode
}

\author{
Yongchun Zhu ${ }^{1 *}$, Yanjia Zhang ${ }^{1}$, Jingyi Li ${ }^{2}$, Yanli Han ${ }^{1}$, Guobin Dong ${ }^{1}$, Hongbo Zhang ${ }^{1}$ \\ ${ }^{1}$ College of Chemistry and Life Science, Shenyang Normal University, Shenyang, China \\ ${ }^{2}$ Foreign Language Department, Shenyang Agricultural University, Shenyang, China \\ E-mail: yongchunzhu@126.com, *yongchunzhu@126.com \\ Received April 28, 2011; revised May 3, 2011; accepted June 7, 2011
}

\begin{abstract}
Melamine as an important chemical raw material and a harmful additive in foods has attracted many people's attention. In the present paper, The graphite-epoxy composited solid phase electrode was modified with bismuth layer by cyclic voltammetric deposition of bismuth from $\mathrm{Bi}\left(\mathrm{NO}_{3}\right)^{3}$ aqueous solution including $0.10 \mathrm{M}$ $\mathrm{HNO}_{3}$, and hydrolyzed into micro bismuthyl chloride on-sites. Melamine in fresh milk was extracted with solid phase micro-extraction on the bismuthyl chloride modified graphite-epoxy composited solid electrode. The adsorption of melamine on bismuthyl chloride particle surfaces follows a Freundlich adsorption model, and results in the decrease of the reduction peak current of bismuth in bismuthyl chloride, and determined by differential pulse voltammetry from fresh milk in a larger concentration range of $10^{-4} \sim 10^{-12} \mathrm{M}$ with detection limit of $2.5 \times 10^{-12} \mathrm{M}$ and relative standard deviation of $2.7 \%$. The method is sensitive, convenient and was applied in the detection of melamine in fresh milk with relative deviation of $4.2 \%$ in content of 0.45 $\mathrm{mg} / \mathrm{kg}$ melamine in the fresh milk.
\end{abstract}

Keywords: Melamine, Bismuthyl Chloride Modified Electrode, Adsorption, Differential Pulse Voltammetry, Solid Phase Micro Extraction

\section{Introduction}

Melamine (2,4,6-triamino-1,3,5-triazine), as an important chemical raw material, has been widely used in the production of plastics[1-4], paper finishers [5], flame retardant [6], and wrinkle-free textiles[7] in the manufacture as well as nano materials [8-10]. Recent case of the discovery of melamine as one of the harmful additives in pet food, animal feed, milk and protein sources including wheat gluten, rice protein concentrate, and corn gluten results in an urgent need for rapid detection methods of melamine in foods [11-13]. The common methods for detection of melamine have been recommended as $\mathrm{GC} /$ MS [14], LC/MS [15,16], as well as the specific antigen-antibody reaction and immune chromatography analysis technology $[17,18]$. All these methods are instruments expensive and time consuming. Electrochemical methods are not favorable for detection of melamine due to its electrochemical inertness. So to find out a suitable chemical modified electrode for extraction, preconcentration and detection of melamine is the key point in electrochemical detection of melamine. Melamine as an aromatic polyamine molecule can interact with ployhydroxides or polyphenol molecules, such as bismuth oxides, bismuthyl chloride molecules through the hydrogen bond formation. Electrochemical deposited bismuth electrode has been used conveniently in electrochemical analysis $[19,20]$. The deposited bismuth hydroxides or bismuthyl chloride may be favourable in the extraction and electrochemical detection of melamine.

In the present paper, the bismuthyl chloride film modified solid phase graphite-epoxy carbon paste electrode was prepared for the electrochemical solid phase micro extraction. Melamine from fresh milk was electrochemically determined, and reported here. 


\section{Experimental Section}

\subsection{Instrumentals}

The electrochemical experiments were carried out on an Electrochemical Analyzer (model CHI620, USA) with three-electrode system, a piece of platinum wire as account electrode, a home-made solid state graphite-epoxy composited electrode as the working electrode, a $\mathrm{KCl}$ saturated calomel electrode (SCE) as the reference electrode. All potentials reported here were respect to this reference electrode.

\subsection{Reagents}

Bismuth nitrate was prepared into $1.0 \mathrm{mM}$ stock solution for the modification of electrode. Potassium chloride was prepared into 1.0 M stock solution as the electrolyte solution. Disodium hydrogen phosphate and citric acid were prepared into $0.2 \mathrm{~mol} / \mathrm{L}$ for $\mathrm{pH}$ buffer solution in the range of 2.2 - 8.0. All chemicals were analytical pure, and purchased from Shenyang Chemical Co. All solutions were prepared with ultrahigh pure water (18.2 M $\Omega$, from Milli-QA-10, Millipore Corporation, Billerica, USA). All electrolyte solution was deaerated with high purity nitrogen gas to remove oxygen prior to use.

\subsection{The Preparation of Basic Electrode}

The basic electrode was prepared by mixing Graphite power (200\#, spectral pure), epoxy resin and polyamide resin into a paste with a weight ratio of $8: 2: 2$, tightly pressed into a clean glass tube (inner diameter is about 4 $\mathrm{mm}$ ) with a copper wire at the other end as an electrode lead, and solidified in air for 72 hours. The prepared graphite-epoxy composite electrode (GECE) was polished on sandpapers (400\#, 600\#, 1000\#) successively, and then polished with glassy paper into mirror surface, as the basic electrode.

\subsection{The Modification of the GECE with Bismuthyl Chloride}

The prepared GECE was set up in $1.0 \mathrm{mM}$ Bismuth nitrate solution with $1.0 \mathrm{M}$ nitric acid as electrolyte and $\mathrm{pH}$ buffer solution. Cyclic voltametric experiments were performed in the potential range of $0.0-1.0 \mathrm{~V}$ at $0.1 \mathrm{~V} / \mathrm{s}$ scan rate in 1000 cycles for the deposition of bismuth on the electrode surface. After the electrochemical deposition, the GECE surface was uniformly covered with bismuth layer. The bismuth modified GECE was washed with Ultrapure water, set into $0.50 \mathrm{M} \mathrm{KCl}$ electrolyte solution, and perform the $\mathrm{CV}$ experiments in the poten- tial range of $-0.2-1.6 \mathrm{~V}$ at $0.1 \mathrm{~V} / \mathrm{s}$ scan rate in $100 \mathrm{cy}-$ cles for the oxidation of bismuth layer. During the oxidation process, the deposited bismuth layer was oxidized into bismuth ion, hydrolyzed into bismuth hydroxide and transformed into a bismuthyl chloride film in-situ as the working electrode used in the following experiments.

\section{Results and Discussion}

\subsection{The Electrochemical Behavior of the Modified Electrodes}

The Bismuth modified GECE electrode in $0.50 \mathrm{M} \mathrm{KCl}$ electrolyte solution gives a CV curve with an irreversible reduction peak at $-0.65 \mathrm{~V}$ and an irreversible oxidation peak at $0.30 \mathrm{~V}$ as shown in curve 2 of Figure 1(a). After the transformation of modified electrode from bismuth layer to bismuthyl chloride layer, the modified electrode gives a typical CV curve as shown in curve 1 of Figure 1(b). The irreversible reduction peak shifts to $-1.42 \mathrm{~V}$ without oxidation peak. The reduction peak potential difference of $0.768 \mathrm{~V}$ between $\mathrm{Bi}^{3+}$ and $\mathrm{BiOCl}$ was used to calculate the solubility product constant of $\mathrm{BiOCl}$ as $1.8 \times 10^{-31}$ [21], which indicates the bismuthyl chloride is very stable. The bismuthyl chloride modified GECE was set into $0.50 \mathrm{M} \mathrm{KCl}$ electrolyte solution including 5.0 $\times 10^{-4} \mathrm{M}$ melamine for $20 \mathrm{~min}$, and then performed cyclic voltammetric experiment. A typical CV curve with the one reduction peak located at $-1.44 \mathrm{~V}$ was obtained as shown in curve 2 of Figure 1(b). The further negative shift of the reduction peak potential indicates the bonding between bismuthyl and melamine is more stable than that of bismuthyl chloride, which is the basic of the solid phase extraction.

The cyclic voltammetric experiments were performed at different scan rates, the obtained reduction peak current was plotted against scan rate, and a straight line was obtained with regression equation of,

$$
i_{\mathrm{pc}} / \mu A=10.18+684.2 \mathrm{v} /\left(\mathrm{V} . \mathrm{s}^{-1}\right)
$$

The correlation coefficient and standard deviation of the regression were 0.9968 and 1.885 , respectively. This relationship indicates that the electrochemical reaction is a surface controlled process, and the reduction reaction occurs at the electrode surface. The all process of the electrode reactions can be summarized in the following equation.

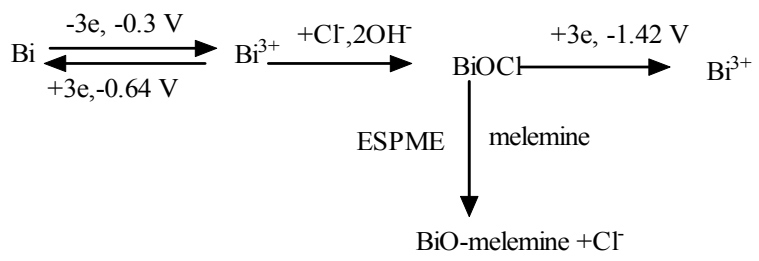




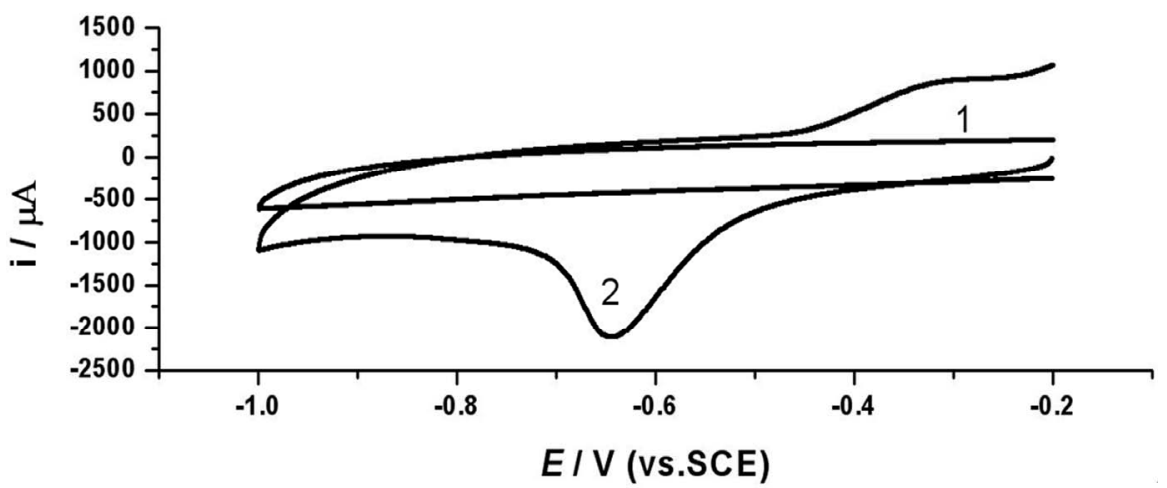

(a)

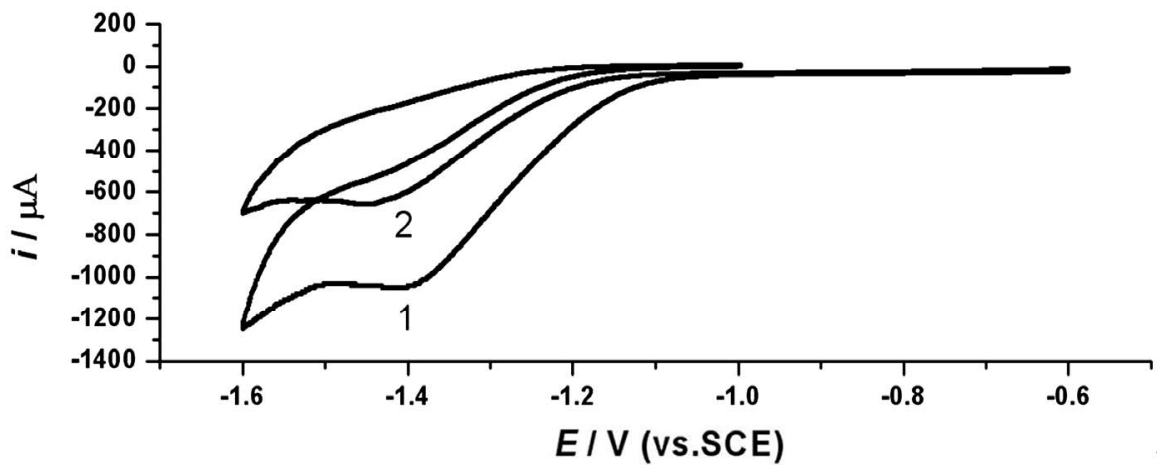

(b)

Figure 1. (a) CV curves of GECE before the bismuth deposited (1) and after the Bismuth deposited (2) in nitric acid solution. (b) CV curves of bismuth modified GECE in $0.5 \mathrm{M} \mathrm{KCl}$ solution(1) and including $5.0 \times 10^{-4} \mathrm{M}$ melamine (2). scan rate: 0.05 V/s.

\subsection{The Effect of Deposition Amount of Bismuth}

The deposition amount of bismuth is very important for the modification of the GECE surface and extraction of melamine. In the cyclic voltammetric deposition process, at the given scan rate $(0.10 \mathrm{~V} / \mathrm{s})$ and potential range of $-0.20--1.6 \mathrm{~V}$, the amount of the deposited bismuth and the effective area of the deposited layer are related to the number of cycles. In order to obtain a bismuthyl chloride layer with larger effective area for extraction of melamine, the modified electrode was checked with cyclic voltammetry in $0.50 \mathrm{M} \mathrm{KCl}$ electrode solution $(\mathrm{pH} \mathrm{6.0)}$ after modification. The reduction peak current of bismuthyl chloride at $-1.42 \mathrm{~V}$ plotting against number of scanning cycles (n) in the deposition step, a one-peak curve with the peak point located at 2000 cycles was obtained as shown in Figure 2. The curve can be regressed into a Gaussian function of,

$$
i_{\mathrm{pc}} / \mu A=155.7 \times \exp \left[\frac{(-2323-n)}{1.3396 \times 10^{6}}\right]
$$

The correlation coefficient and standard deviation of the regression were 0.9812 and 12.9 , respectively. This result indicates the effective area of electrode surface for the formation of effective bismuthyl chloride layer and extraction of melamine increases with the increase of scanning cycles at the beginning of the deposition, but after about 2000 cycles, but it is reduced after more and more bismuth deposited from solution. So 2000 cycles was set as the optimal deposition condition.

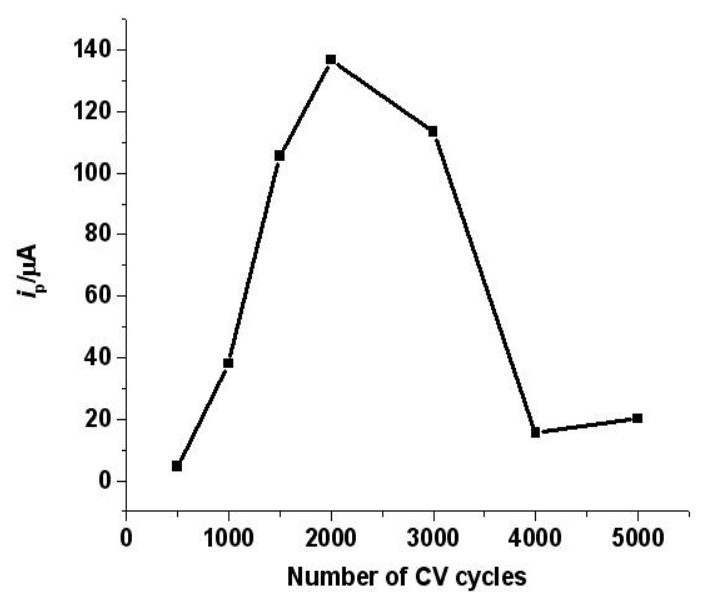

Figure 2. The relationshp between reduction peak current and number of $\mathrm{CV}$ cycles. The experimental conditions were the same as those in Figure 2. 


\subsection{The Effect of Solution pH}

Melamine is a weak acid with $\mathrm{pk}_{\mathrm{a}}$ of 5.35 [22], and bismuthyl chloride is transferred from bismuth hydroxide, So solution $\mathrm{pH}$ is very important for the formation of bismuthyl chloride layer and extraction of melamine. The solution $\mathrm{pH}$ was controlled by disodium hydrogen phosphate-citric acid buffer system in the range of 4.0 8.0. The PDV experiments were performed on the bismuthyl chloride modified electrode in the solutions with different $\mathrm{pH}$ after setting the electrode in the solution for $4 \mathrm{mins}$ and at initial potential of $-0.6 \mathrm{~V}$ for $100 \mathrm{~s}$. The obtained reduction peak current at $-1.32 \mathrm{~V}$ plotted against solution $\mathrm{pH}$ is one-peak curve with the maximum point at $\mathrm{pH}=6.0$ as shown in Figure 3 .

These results indicate that in the case of $\mathrm{pH}=\mathrm{pK}_{\mathrm{a}}$, melamine is suitable for the interaction with bismuthyl chloride by hydrogen bonding. Bismuthyl chloride is come from bismuth hydroxide, which has a solubility product constant of $4.0 \times 10^{-31}$, pH6.0 is also included enough concentration of hydroxide ion for the formation of bismuth hydroxide, and stabilized the bismuthyl chloride. So the optimal solution $\mathrm{pH}$ was chosen as $\mathrm{pH}=6.0$.

\subsection{The Effect of Quiet Time}

Quiet time is the period time applying the initial potential to the electrodes before potential scanning, which can be used to test the influence of initial potential on extraction of melamine. The electrodes were set into $0.5 \mathrm{M} \mathrm{KCl}$ solution including $5.0 \times 10^{-4} \mathrm{mM}$ melamine, at initial potential of $-0.6 \mathrm{~V}$ for different quiet time, and then PDV experiments were performed in the potential range of $-0.60 \mathrm{~V}--1.50 \mathrm{~V}$. The obtained reduction peak current at $-1.32 \mathrm{~V}$ plotting against quiet time, a curve was obtained as shown in Figure 4. The first part of the curve in quiet time range of $0-40 \mathrm{~s}$ was a straight line with the regression equation of,

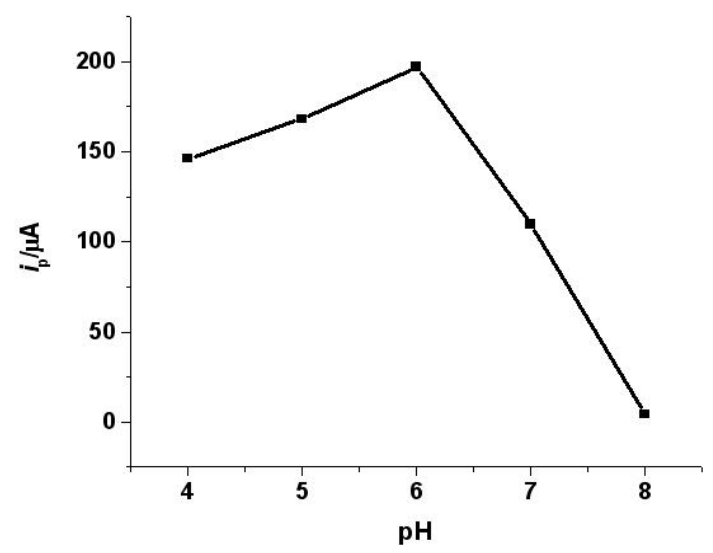

Figure 3. The relationship between reduction peak current and solution $\mathrm{pH}$.

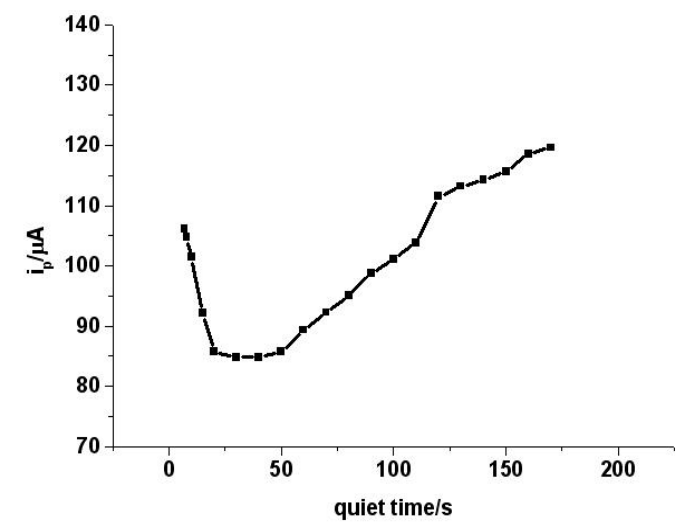

Figure 4. The relationship between reduction peak current and quiet time.

$$
\begin{aligned}
& i_{\mathrm{pc}} / \mu A=117.3-1.608 t / s, \\
& \mathrm{R}=0.9974, \mathrm{SD}=0.7255
\end{aligned}
$$

The correlation coefficient and standard deviation of the regression were 0.9974 and 0.7255 , respectively. The rest part of the curve in quiet time range of $40-170 \mathrm{~s}$ was a S-shaped curve, and can be regressed as a Rechards model with an equation of,

$$
i_{\mathrm{pc}} / \mu A=\frac{120.0}{\left[1+\exp (12.08-0.082 t / s)^{0.041}\right]}
$$

The correlation coefficient and standard deviation of the regression were 0.9958 and 1.29 , respectively, and the inflection point located at $120 \mathrm{~s}$. This relationship indicates the process is greatly influenced by initial potential due to the initial state of bismuthyl chloride and its interaction with melamine. With the increase of quiet time, the extraction amount of melamine increases so the reduction peak current decreases. The initial potential $-0.6 \mathrm{~V}$ is also the potential for bismuth ion pre-reduced into bismuth, which can increase the reduction peak current without influence on melamine extraction. So in practice, the optimal quiet time was chosen at the inflection point of $120 \mathrm{~s}$.

\subsection{The Effect of Accumulation Time}

Accumulation time is the period time of contacting electrode to melamine aqueous solution before the beginning of the electrochemical experiment. Accumulation time is also the extraction time without influence of initial potential. The electrodes were set into $0.50 \mathrm{M} \mathrm{KCl}$ solution including $5.0 \times 10^{-4} \mathrm{M}$ melamine for different accumulation time, and then PDV experiments at $-0.60 \mathrm{~V}$ initial potential and quiet time of 120 s were performed in the potential range of $-0.60 \mathrm{~V}--1.50 \mathrm{~V}$. The obtained reduction peak current at $-1.32 \mathrm{~V}$ was plotted against accu- 
mulation time, a curve was obtained as shown in Figure 5.

The curve was regressed as a Boltzman function model with an equation of,

$$
i_{\mathrm{pc}} / \mu A=82.0-\frac{147.3}{\left[1+\exp \left(\left(t_{\mathrm{accum}} / \min -3.2\right) / 0.381\right)\right]}
$$

The correlation coefficient and standard deviation of the regression were 0.9995 and 2.25 , respectively. This relation indicates that the melamine molecules were extracted on bismuthyl chloride surface, and decreased the reduction peak current of bismuthyl chloride with a inflection point at $3.2 \mathrm{~min}$. So in practice, the accumulation time of $4 \mathrm{~min}$ is enough for the reaction to reach the saturated state.

\subsection{The Effect of Melamine Concentration}

Under the optimal experimental conditions such as solution $\mathrm{pH} 6.0$, initial potential of $-0.60 \mathrm{~V}$, quiet time of 120 $\mathrm{s}$, accumulation time $4 \mathrm{~min}$, PDV experiments were performed at different concentration of melamine. The obtained reduction peak current at $-1.32 \mathrm{~V}$ sharply decreases with the increase of melamine concentration known as the isothermal adsorption curve shown in Figure 6.

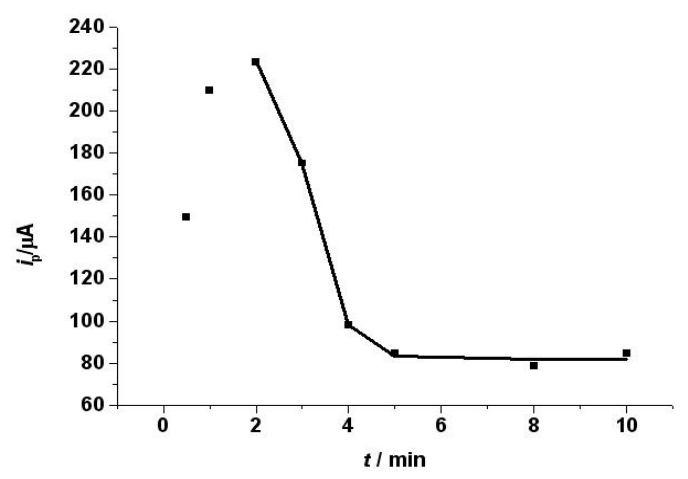

Figure 5. The relationship between reduction peak current and accumulation time.

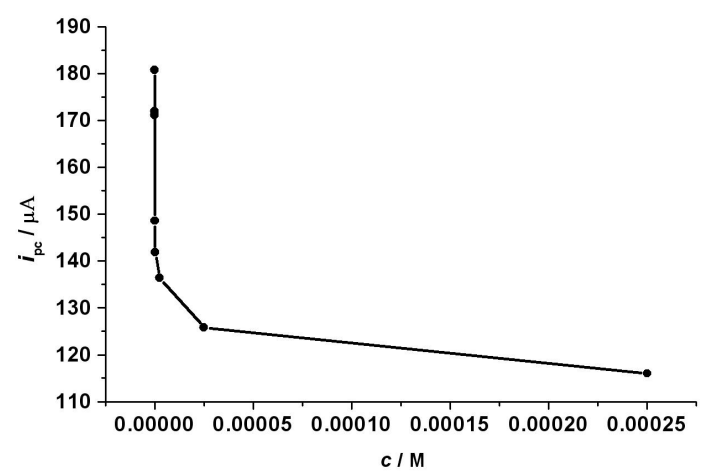

Figure 6. The relationship between reduction peak current and melamine concentration.
The curve was regressed as a logarithm model with an equation of,

$$
i_{\mathrm{pc}} / \mu A=88.94-8.042 \times \log (c / \mathrm{M})
$$

The correlation coefficient and standard deviation of the regression were 0.9925 and 3.09 , respectively. The logarithm of reduction peak current, $i_{\mathrm{pc}}$, against the logarithm of melamine concentration was a linear line with a regression equation of

$$
\begin{aligned}
& \log \left(i_{\mathrm{pc}} / \mu A\right)=1.992-0.0236 \log (c / \mathrm{M}), \\
& R=0.989 ; S D=0.011
\end{aligned}
$$

This relation indicates the adsorption of melamine molecule on the electrode surface follows Freundlich adsorption model [23] with the adsorption equilibrium constant of $\mathrm{K}=98.2$, and $\mathrm{n}=42.4$, which is a favourable adsorption process.

\subsection{The Standard Curve and Deviation of the Method}

In order to determine the concentration of melamine in aqueous solution, the Equation (7) was also served as the standard working curve. The detection limit (in the ratio of signal to noise $3: 1$ ) was calculated as $2.5 \times 10^{-12} \mathrm{M}$ with the relative standard deviation of $2.7 \%$ in the concentration range of $2.5 \times 10^{-12}-2.5 \times 10^{-4} \mathrm{M}$.

\subsection{The Detection of Melamine in Fresh Milk}

The Huishan fresh milk (made in Shenyang Huishan milk Co.) was bought from supermarket. The test solution was the mixture of $5.0 \mathrm{~mL}$ fresh milk, $5 \mathrm{~mL}$ disodium hydrogen phosphate-citric acid buffer solution $(\mathrm{pH}$ 6.0) and $10.0 \mathrm{~mL} \mathrm{KCl}$ electrolyte solution. The PDV experiments were carried out under the optimal conditions: solution $\mathrm{pH} 6.0$, the accumulation time of $4 \mathrm{~min}$, and initial potential of $-0.60 \mathrm{~V}$ for $50 \mathrm{~s}$. the experiments were parallel for 5 times, the average reduction current at $-1.32 \mathrm{~V}$ was obtained as $1.626 \mu \mathrm{A}$ with the relative deviation of $4.2 \%$. The amount of melamine in the fresh milk was calculated as $0.45 \mathrm{mg} / \mathrm{kg}$. According to the national standard, the melamine in fresh milk is less than $1 \mathrm{mg} / \mathrm{kg}$. So the tested fresh milk sample met the requirement standard.

\section{Conclusions}

As a summary of this work, a graphite-epoxy composite electrode was modified electrochemically by bismuthyl chloride in-situ. The bismuthyl chloride layer serves as a solid phase micro extractant, extracts melamine from aqueous solution with the help of electrochemistry. The 
adsorption of melamine on bismuthyl chloride flows Freundlich adsorption model, and results in the decrease of reduction current of bismuthyl chloride, and used for the determination of melamine in the range of $10^{-4} \sim$ $10^{-12} \mathrm{M}$ with detection limit of $2.5 \times 10^{-12} \mathrm{M}$ and relative standard deviation of $2.7 \%$.This method offers new way for the electrochemical detection of electrochemically inactive species.

\section{Acknowledgements}

The author would like to acknowledge the financial supports of the Chinese National Science Foundation (20875063), Liaoning education minister (2004-c022) and national key. Laboratory on electroanalytical chemistry (2006-06), Shenyang Sciences and technology bureau foundation (2007-GX-32).

\section{References}

[1] S. V. Levchik and E. D. Weil, "Flame Retardancy of Thermoplastic Polyesters: a Review of the Recent Literature," Polymer International Vol. 54, No. 1, January 2005, pp. 11-35. doi:org/10.1002/pi.1663

[2] Z. Wirpsza, "Achievements in the Use of Melamine as a Chemical Raw Material. Part I. General Review and Melamine-Based Coating Resins and Coatings," Polimery, Vol. 41, No. 5, June 1996, pp. 265-276.

[3] H. Walch, A. Maier, W. M. Heckl and M. Lackinger, "Isotopological Supramolecular Networks from Melamine and Fatty Acids," The Journal of Physical Chemistry C, Vol. 113, No. 3, March 2009, pp. 1014-1019. doi:org/10.1021/jp8078474

[4] M. Henriksson and L. A. Berglund, "Structure and Properties of Cellulose Nanocomposite Films Containing Melamine Formaldehyde," Journal of Applied Polymer Science, Vol. 106, No. 4, November 2007, pp. 2817-2824. doi:org/10.1002/app.26946

[5] U. Berger and W.Schnick, "Syntheses, Crystal Structures, and Vibrational Spectroscopic Properties of $\mathrm{MgCN}_{2}$, $\mathrm{SrCN}_{2}$, and $\mathrm{BaCN}_{2}$," Journal of Alloys and Compounds Vol. 206, No. 2, May 1994,pp. 179-184. doi:org/10.1016/0925-8388(94)90032-9

[6] M. Groenewolt and M. Antonietti, "Synthesis of $\mathrm{g}-\mathrm{C}_{3} \mathrm{~N}_{4}$ Na-Noparticles in Mesoporous Silica Host Matrices," Advanced Materials, Vol. 17, No. 14, July 2005, pp. 1789-1792. doi:org/10.1002/adma.200401756

[7] E. Kroke and M. Schwarz, "Novel Group 14 Nitrides," Coordination Chemistry Review, Vol. 248, No.5-6, 2004, pp. 493-532.

[8] L. Licea-Jiménez and R. W. Rychwalski, "Novel Nanocomposites Using Carbon Nanotubes and Melamine-Formalde-Hyde," Materials Science-Poland Vol. 23, No. 4, January 2005, pp. 909-913.

[9] S. Bajia, R. Sharma and B. Bajia, "Solid-State Microwave Synthesis of Melamine-Formaldehyde Resin," Solid State Microwave Synthesis, Vol. 6, No. 1, January 2009, pp. $120-124$.

[10] A. K. Hau, T. H. Kwan and P. K. Li, "Melamine Toxicity and the Kidney," Journal of American Society of $\mathrm{Ne}$ phrology, Vol. 20, No.2, February 2009, 245-250. doi:org/10.1681/ASN.2008101065

[11] D. Meter and R. J. Hemley, "Low-Compressibility Carbon Nitrides," Science, Vol. 271, No. 5245, January 1996, pp. 53-55.

[12] S. Ehling, S. Tefera and I. Pho, "Rapid Nondestructive Screening for Melamine in Dried Milk by Raman Spectroscop," Food Additives and Contaminations, Vol. 24, No. 12, November 2007, pp. 1319-1325.

[13] S. Mfiligenzi, B. Puschner and L. S. Aston, "Diagnostic Determination of Melamine and Related Compounds in Kidney Tissue by Liquid Chromatography/Tandem Mass Spectrometry," Journal of Agricultural Food Chemistry, Vol. 56, No. 17, September 2008, pp. 7593-7599. doi:org/10.1021/jf801008s

[14] J. J. Litzau, G. E. Mercer and K. J. Mulligan, "GC-MS Screen for the Presence of Melamine, Ammeline, Ammelide and Cyanuric Acid," US FDA Laboratory Information Bulletin, No. 4423, October 2008. http://www.cfsan.fda.gov/ frf/ lib4423.html.

[15] M. Smoker and A. J. Krynitsky, "Interim Method for Detemination of Melamine and Cyanuric Acid in Food Using LC/MS-MS," Version 1.0. US FDA Laboratory Information Bulletin, No. 4422, October 2008. http://www.cfsan.fda.gov/ frf/lib4422.html.

[16] S. Turnipseed, C. Casey, C. Nochetto and D. N. Heller, "Determination of Melamine and Cyanuric Acid Residues in Infant Formula Using LC-MS/MS," US FDA Laboratory Information Bulletin, No. 4421, October 2008. http://www.cfsan.fda.gov/ frf/lib4421.html.

[17] J. V. Sancho, M. Ibanez and S. Grimalt, "Residue Determination of Cyromazine and Its Metabolite Melamine In Chard Samples by Ion-Pair Liquid Chromatography Coupled to Electrospray Tandem Mass Spectrometry," Anayticall Chimica Acta, Vol. 530, No. 2, February 2005, pp. 237-243.

[18] H. Ogasawara, K. Imaida and H. Ishiwata, "Urinary Bladder Carcinogenesis Induced by Melamine in F344 Male Rats: Correlation between Carcinogenicity and Urolith formation," Carcinogenesis, Vol. 16, No. 11, November 1995, pp. 2773-2777.

[19] N. Serrano, N. Martin, J. Diaz-Cruz, C. Arino and M. Esteban, "Bismuth Film Electrode in Metal Complexation Studies: Stripping Analysis of the $\mathrm{Pb}(\mathrm{II})-, \mathrm{Cd}(\mathrm{II})-$, and Zn(II)- Binding with Phthalate," Electroanalysis, Vol. 21, No. 3-5, February 2009, pp. 431-438.

[20] F. Torma, A. Grun, I. Bitter and K. Toth, "Calixarene/ Nafion-Modified Bismuth-Film Electrodes for Adsorptive Stripping Voltammetric Determination of Lead," Electroanalysis, Vol. 21, No. 17-18, September 2009, pp. 1961-1969.

[21] Solubility Products at $25^{\circ} \mathrm{C}, 11 / 28 / 2007$ http://www.csudh.edu/Oliver/chemdata/data-ksp.htm.

[22] U. S Food and Drug Administration, "Interim Melamine and Analogues Safety/Risk Assessment," 05/22/2009 http://www.fda.gov/ScienceResearch/SpecialToics/PeerRev iew of Scientific Information and Assessments/ucm 155012. 
htm.

[23] J. T. Nwabanne and P. K. Igbokwe, "Kinetics and Equilibrium Modeling of Nickel Adsorption by Cassava
Peel," Journal of Engineering Applied Science, Vol. 3, No. 11, November 2008, pp. 829-834. 